\title{
Research on Influence of High-tech Manufacturing on Higher Education
}

\author{
Sheng Han Zhou ${ }^{1}$, Jia Ning Zhang ${ }^{1}$, Wen Bing Chang ${ }^{1 *}$, Jun Zhao ${ }^{2}$ \\ ${ }^{1}$ School of Reliability and Systems Engineering, Beihang University, Beijing 100191 \\ ${ }^{2}$ School of Economics and Management, Beihang University, Beijing 100191 \\ *Corresponding author, Changwenbing@263.net
}

\begin{abstract}
Keywords: Higher Education, High-Tech Manufacturing; Least Squares Regression; Ridge Regression
\end{abstract}

\begin{abstract}
This study explores the influence of high-tech manufacturing on higher education on the basis of quantitative analysis using the ridge regression. In order to reach the goal, relevant indicators and data collected during the year 2005-2012 are integrated into four invariables: economic development (ED), funding support (FS), manufacturing factor (MF) and education factor (EF). Original data could not meet the analysis needs, therefore, several data process methods are proposed. Subsequently, ridge regression model is established based on factor analysis and correlation analysis. The model indicates that high-tech manufacturing has a positive effect on the development of higher education. At last, further analysis between high-tech manufacturing and higher education is made and several suggestions are put forward to the better development of high-tech manufacturing and higher education.
\end{abstract}

\section{Introduction}

Higher education occupies an important position during the national long-term development and plays a key role on social development and economic construction by cultivating high level talents. According to the "Chinese Statistical Yearbook", more than 480 thousand of graduate students graduate in China and the number of graduates is over 3 million in 2012, which breaks a new record in the Chinese history of higher education. However, the proportion of employees in manufacturing industry received higher education is less than 10 percent, which means the education level of practitioners in manufacturing industry in China is relatively low. The low level of education, limits the development of China's manufacturing industry, causes a great waste of educational resources and restricts the development of higher education in china.

Sui $^{[1]}$ proposed the six primary factors affecting the development of higher education: politics, economics, science and technology, population, culture and the support of education foundation. After several decades of development, China's political, economic and other aspects make a significant progress. Although the educational environment and concept have changed, but the main influence factors of higher education has not changed. Subsequently, some studies explored the impact of the economy on higher education further, such as the literature ${ }^{[2-8]}$. Manufacturing industry, as an important pillar industry of economic development, the study of which influence on the higher education is not too much. As Ren ${ }^{[9]}$ drew a conclusion that Chinese manufacturing enterprises may not need the high level talents in the present with the data of industrial enterprises in the year 2004. However, whether it can reflect the real development situation of the manufacturing industry remains to be discussed considering the old data. $\mathrm{Xu}^{[10]}$ argued the high correlation between high-tech manufacturing industry and higher education scale based on the economic data of 2004-2009 years in Guangdong Province. Ayla ${ }^{[11]}$ also suggested the close relationship between industry and higher education, from the perspective of cooperation between university and enterprises. This paper aims to explore the influence of high-tech manufacturing industry on higher education from the prospective of national level by the method of ridge regression with the latest data of 2005-2012 years. 


\section{The Present Situation of Higher Education and Manufacturing Industry}

The Rapid Development of Higher Education. "For the Twenty-First Century Action Plan for Invigorating Education" in 2010 established a goal that the enrollment ratio of higher education would be close to $15 \%$. In fact, the scale of undergraduate and graduate has been greatly improved, since the large scale expansion of higher education, such as the number of graduate students in 2005 is 970,000 , in 2012 the number grew to 1,720,000, almost doubled in seven years.

In terms of educational resources, the number of teachers in colleges and universities has increased year by year, the growth rate of teachers and students almost synchronous. In 2005, the number of full-time teachers in universities and colleges is 965,839, in 2012 the number increased to 1,440,292, an increase of $49 \%$; in 2005 the number of undergraduate students is $8,488,188$ and the number of graduate students is 978,610 , in 2012 the number increased to 14,270,888 and 1,719,818, an increase of respectively $68 \%$ and $76 \%$. From the ratio of the sum of undergraduate and graduate students in the school and the sum of the full-time teachers, in 2005 is 9.8 and in 2012 became 11.1, indicating the ratio has modest growth, which means that the number of the teachers is able to meet the rapid growth of the demand of the teaching caused by the increase of students.

The Low Level of High-Tech in Manufacturing Industry. In the economic globalization of industrial division, the developed countries occupy the industrial chain upstream, mainly engaged in high-tech industry; while the developing countries including China occupy the downstream industrial chain, mainly engaged in low technology industry ${ }^{[9]}$. Lang puts forward the famous industrial chain theory of "6+1", within which "6" refers to the product design, raw materials procurement, storage and transportation, order processing, wholesale business and retail and " 1 " indicates the product manufacturing, which constitute the 7 aspects of the industrial chain. As the world manufacturing factory, China's manufacturing industry is more of the role reaping the lowest profit ${ }^{[12]}$.

China's 19 major industry data shows, during 2005-2012, in terms of the number of employees in urban, manufacturing industry has been ahead of the other 18 industries, ranking the first; besides, manufacturing value added accounted for the total value of $30 \%$, ranking the first in the industry which reflects its advantage in terms of scale and economic status. In regard to the level of education of employees in manufacturing industry, China's level of education is obviously low compared with American. As shown in Table $1^{[13]}$.

Table 1 Comparison between China and America in education

\begin{tabular}{|c|c|c|c|}
\hline \multicolumn{2}{|c|}{ Manufacturing industry } & $\begin{array}{l}\text { China } \\
(2010)\end{array}$ & $\begin{array}{l}\text { America } \\
(2006)\end{array}$ \\
\hline \multirow{4}{*}{$\begin{array}{c}\text { The } \\
\text { distribution } \\
\text { of education } \\
(\%)\end{array}$} & total & 100 & 100 \\
\hline & $\begin{array}{c}\text { junior high school } \\
\text { and below }\end{array}$ & 70.1 & 13.6 \\
\hline & high school & 20.1 & 54.4 \\
\hline & $\begin{array}{l}\text { college degree } \\
\text { and above }\end{array}$ & 9.8 & 32 \\
\hline The average & $\begin{array}{l}\text { level of education } \\
\text { year) }\end{array}$ & 9.8 & 13.2 \\
\hline
\end{tabular}

From table 1, the ratio of college degree and above in manufacturing industry in China is less than $10 \%$, while the same index in American is nearly 1/3. The huge gap between the levels of education is the fundamental reason why the manpower cost is too low in China and also the basic reason that China's high-tech level is below American's.

China higher education develops rapidly and will provide a large number of high level talents for the society in future. However, the economics status of manufacturing cannot keep consistence with the level of education of its employees and the trends of development of higher education. High-tech 
manufacturing, as a key part of manufacturing, is the important guarantee of the promotion of manufacturing industry, an indispensable field of attracting high level innovative talents, but also an significant driving force of higher education personnel training. Therefore, it is of great significance to study the influence of high-tech manufacturing on higher education for the transformation and upgrading of the manufacturing industry and the development of higher education.

\section{Analysis of Effect of High-Tech Manufacturing on Higher Education}

The Selected Variables. In view of the existing literature emphasizing the influence of economic development on higher education, select GDP as the first explanatory variable (ED). At the same time, the education funds support also affect the development of higher education inevitably, select the national financial education expenditure as the second explanatory variable (FS). This paper focuses on the influence of high-tech manufacturing on higher education, select the high-tech manufacturing factor as the third explanatory variable (MF). Finally, the higher education factor is set as the dependent variable (EF). It should be noted that high-tech manufacturing factor (referred to as the manufacturing factor later) and higher education factor (referred to as the education factor later) both include several indicators. As shown in Table 2. Data is from the "Chinese Statistical Yearbook" (2006-2013), "Chinese statistical yearbook on science and technology" (2012) and "China High-tech Industry Statistical Yearbook" (2013). Limited to data integrity, screen out part of the data of 2005-2012 for the study.

Table 2 Invariables and indicators

\begin{tabular}{cc}
\hline Invariables & Indicators \\
\hline Economic Development (ED) & GDP \\
Funding Support (FS) & The national financial education expenditure \\
& The number of graduate students in the school (NG) \\
The number of ordinary undergraduates (NU) \\
The number of overseas students in school (NO) \\
Education Factor (EF) & The number of study abroad (NA) \\
& The returned personnel (RP) \\
& Scientific papers published abroad (PP) \\
manufacturing value added (MV) & High tech industry export delivery value (HV) \\
Hanufacturing Factor (MF) & High-tech industry total profits (HP) \\
\hline
\end{tabular}

The hypothesis is that economic development has a significant positive impact on higher education, funding support and high-tech manufacturing also has a positive effect on the development of higher education. And the influence can be regarded as linear. The model can be expressed as:

$$
E F=\beta_{0}+\beta_{1} E D+\beta_{2} F S+\beta_{3} M F
$$

Besides, education factor and manufacturing factor can be reflected through several indicators and the relationship between them can be assumed linear. The model can be expressed as:

$$
\begin{gathered}
E F=\alpha_{0}+\alpha_{1} N G+\alpha_{2} N U+\alpha_{3} N O+\alpha_{4} N A+\alpha_{5} R P+\alpha_{6} P P \\
M F=\gamma_{0}+\gamma_{1} M V+\gamma_{2} H V+\gamma_{3} H R+\gamma_{4} H P
\end{gathered}
$$

Data Preprocessing. The original data collected needs preprocessing for it cannot meet the requirements of data analysis. This paper uses the missing value processing, the elimination of price changes and the dimensionless processing. Since manufacturing value added in the year 2012 is missing, a linear trend extrapolation is used for the estimation of the missing value. Considering price 
changes, all price data is unified conversion to the price standard in 2005. In addition, according to the data standard in the year 2005, dimensionless processing is carried out because of the existence of multiple dimensional data, and then the processed data to be analyzed further is obtained.

Data Analysis. Factor analysis is provided to integrate the indicators into manufacturing factor and education factor to reflect the situation of development of high-tech manufacturing and higher education respectively, as shown in Table 2. Correlation analysis is proposed among education factor, manufacturing factor, GDP and state financial education expenditure. Results indicates all correlation coefficients are over 0.99, which means that higher education has a close relationship with the other three factors.

Least square linear regression model is established between EF and MF. With the 0.05 level of confidence, $\mathrm{t}$ test of the coefficient of MF is passed (Sig. $\approx 0$ ). However, the $\mathrm{P}$ value of the constant is 1.0 , over 0.05 , not passing $t$ test. In this model, on one hand it is confirmed the influence of high-tech manufacturing on higher education; on the other hand, the single factor, high-tech manufacturing, cannot explain the situation of higher education perfectly, there exists other factors affecting the higher education and multiple linear regression model is needed to be established. Take $E F$ as the dependent variable, $E D, F S, M F$ as explanatory variables for multiple linear regression analysis. The regression result is:

$$
E F=-2.874+0.693 E D+0.854 F S-0.042 M F
$$

Decision coefficient $R^{2}=0.999$, regression model fits well. The $\mathrm{P}$ value of $\mathrm{F}$ test is nearly 0 , linear equation is significant. While the $\mathrm{P}$ value of $E D$ and $M F$ is 0.142 and 0.775 respectively, not passing t test. The diagnosis of multiple collinearity identifies that there exists serious multiple collinearity among explanatory variables. It is generally believed that if the variance inflation factor $V I F>10$, multiple collinearity appears. In the analysis result, the minimum of $V I F$ is 71 and the maximum is 114 , indicating that serious multiple collinearity appears.

Assuming that the matrix form of multivariate linear regression model: $Y=X \beta+\varepsilon$, OLS estimate of parameters is $\hat{\beta}=\left(X^{T} X\right)^{-1} X^{T} Y$. As for existence of multiple collinearity among explanatory variables, $\left|X^{T} X\right| \approx 0, \hat{\beta}$ is not stable, which leads to low accuracy of estimate. Although the unbiased estimate of $\beta$ can still be obtained by OLS, the estimated value of $\beta$ will produce a great deviation, even turn to be negative numbers not matching with the actual significance ${ }^{[14]}$. Ridge regression adds $X^{T} X$ with a positive constant matrix $k I(k I>0)$, the degree of being singular of $X^{T} X+k I$ is smaller than $X^{T} X$, and then the problem of the instability of estimate of the parameters can be solved well. Thus, the ridge regression is applied for further study to solve the multiple collinearity.

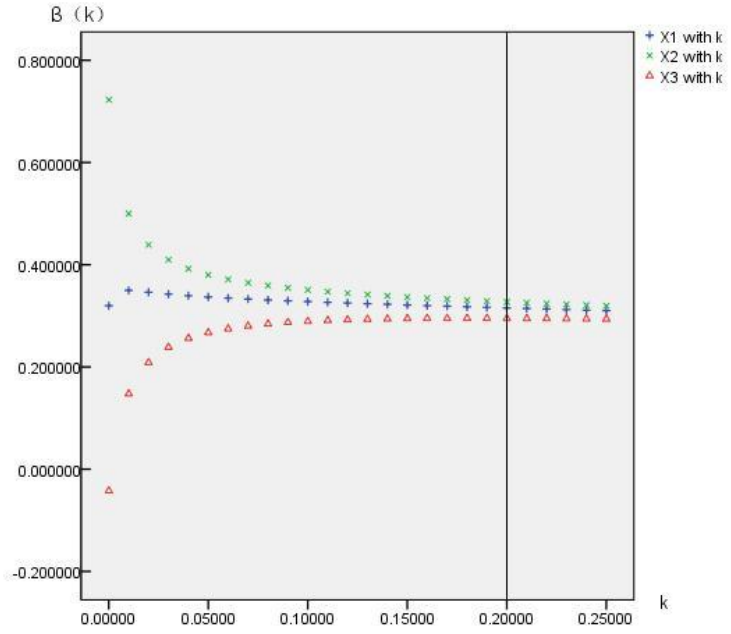

Fig. 1 Ridge trace plot 
As shown in Figure 1, the abscissa implies the values of ridge parameter $k$; the ordinate indicates the estimate value of coefficients of ED, FS, MF; discrete points demonstrate the changes of coefficients under different ridge parameters. It is obviously when the ridge parameter $k=0.2$, the coefficients estimate value of three explanatory variables tends to be stable, thus the ridge estimate is optimal. Ridge regression result is:

$$
E F=-1.90+0.6832 E D+0.3867 F S+0.2951 M F
$$

Among them, $E D$ stands for economic development, $F S$ for the funding support, $M F$ for manufacturing factor, $E F$ for education factor. It can be seen from the ridge regression result, coefficient of $E D$ is positive and the largest in all the variables' coefficients, showing that economic development has a significant role in promoting to higher education; and the coefficients of $F S$ and $M F$ are positive, implying that funding support and high-tech manufacturing both have a positive impact on the development of higher education; thus the assumption is confirmed.

\section{Discussion}

The development of higher education is influenced by economic development, state financial education funds support and the development of high-tech manufacturing. Among them, economic development is the most primary influence factor.

The national financial education expenditure, as one of the main sources of higher education funding, often accounts for more than $50 \%$ of total funding of higher education. Powerful capital support can provide high-quality teachers, advanced teaching equipment and excellent teaching environment for higher education, thus promoting the development of higher education. The national financial education expenditure is an important factor to affect the development of higher education.

High-tech manufacturing industry has a certain influence on the development of higher education in China. The development of high-tech manufacturing inevitably promotes technological changes and innovation, the root of which derives from the talents. Meanwhile, it is the responsibility of higher education to provide high level talents with innovative ability for the social development and economic construction. From this perspective, the high-tech manufacturing offers opportunities and direction of development to higher education, and higher education provides the talents for high-tech manufacturing in return. However, the degree of effect of high-tech manufacturing on higher education is inferior to the other two factors. In fact, compared with developed countries, the proportion of high-tech industry R\&D funds in the total industrial output value in China is low apparently, such as America is 19.74\% (2009), Japan 10.50\% (2008), 11.10\% in the UK (2006), and China is only $1.68 \%$ (2012). The results of comparison indicates high-tech manufacturing in China in terms of R \& D and innovation is still weak and need more attention and efforts.

\section{Conclusion}

Through this research, we find some interesting conclusions.

Firstly, the development of high-tech manufacturing, not only can improve the overall level of manufacturing industry to enhance national economic strength, but also the higher education personnel training mode and the output level of talents. So the best way to the better higher education is to develop the high-tech manufacturing vigorously and realize the rapid upgrading of manufacturing.

Secondly, higher education is to cultivate innovative talents of high level for high-tech manufacturing. The development of higher education should attach importance to the development trend of high-tech in manufacturing talent training for high-tech manufacturing development needs, because the process of output talents also is the process of evaluation of higher education quality.

Thirdly, on one hand, provide a healthy political and economic environment for the development of high-tech manufacturing and higher education, establish a typical case of perfect joint between high-tech manufacturing and higher education as an example for other universities and high-tech 
manufacturing; on the other hand, carry out the supervision work of cooperation between high-tech manufacturing and higher education. Both ensure high-tech manufacturing has talents available that adapts to the development needs, and avoid the waste of higher education resources. So we need to strengthen the guidance and supervision of the national policy.

Fourthly, we need to encourage cooperative education between university and enterprises in order to make the high-tech manufacturing qualified and sufficient reserves of talents. And it is necessary to encourage enterprises to take part in teaching and cooperation between university and enterprises in order to make the higher education and high-tech manufacturing develop closely.

The participation of enterprise in higher education not only can share the responsibility with colleges; but also can strengthen the communication between enterprises and university, which is beneficial to exchange ideas in talent training and improve the quality of talent training.

\section{Acknowledgement}

The paper is supported by the Fundamental Research Funds for the Central Universities and the Technical Research Foundation. The study is also sponsored by the National Natural Science Foundation of China (Grant No. 71271014) and the Aviation Science Foundation of China (Grant No.2014ZG51075).

\section{References}

[1] Y.F. Sui: Shanghai Researches on Higher Education, (1991) No.4, p.10.(In Chinese)

[2] Y.X. Zhang and S.L. Wang: Heilongjiang Researches on Higher Education, (2014) No.3, p.31. (In Chinese)

[3] Y.Y. Zhou: An Empirical Study on the Relationship between Higher Education and Economic Growth in China (MS., Industrial and Commercial University of Chongqing, China 2010), p.29. (In Chinese)

[4] J. Wang: An Empirical Study on the Relationship between Economic Growth and the Development of Higher Education (MS., Chongqing University, China 2005), p.5. (In Chinese)

[5] X. Ma and M. Zhang: Finance and Economics, (2001) No.1, p.75. (In Chinese)

[6] H.T. Hava and R. Erturgut: Procedia - Social and Behavioral Sciences, Vol. 2 (2010) No.2, p.1771.

[7] L.P. Wang: Journal of Taiyuan University, Vol.14 (2013), No.4, p.101. (In Chinese)

[8] A.A. Fan and W.Q. Shen: Journal of Hebei University (Education Science Edition), Vol.15 (2013) No.4, p.11. (In Chinese)

[9] J.Q. Ren: Industrial Economics Research, (2013) No.6, p.77. (In Chinese)

[10]X.D. Xu: Industrial Engineering Journal, Vol.15 (2012) No.4, p.96. (In Chinese)

[11]C.D. Ayla and N.E. G Ren: Procedia - Social and Behavioral Sciences, Vol.2 (2010) No.2, p.3437.

[12]C.M. Yu: Education Teaching Forum, (2014) No.13, p.241. (In Chinese)

[13]J.X. Liu and R.W. Hu: Research on Higher Engineering Education, (2013) No.4, p.13. (In Chinese)

[14]W.K. Huang, The Diagnosis and Process Solutions in Multicollinearity of Multiple Regression Model (MS., Harbin Institute of Technology, China 2012), p.12. (In Chinese) 